Zweifach-kohlensaures Ammoniak, $\mathrm{NH}_{4} \mathrm{O}, \mathrm{C}^{2} \mathrm{O}^{4}+\mathrm{HO}$. Es entsteht beim Sättigen des Sesquicarbonats mit Kohlensäure. Fs setzt sich in schönen Krystallen ab, die an der Luft unveränderlich sind und sich genau messen liessen. Die Krystallform, in der Miller'schen Bezeichnung ausgedriickt, ist :

$$
\{101\}\{011\}, 100\}\{010\}\{110\}
$$

Durch beträchtliche Abkühlung einer Lösung des käuflichen kohlensauren Ammoniaks bekommt man abgeplattete prismatische Krystalle, von denen einige Flächen und Kanten gekrümmt sind. Fs ist dasselbe Salz mit 1 Aeq. Wasser.

Nach Rose soll das Salz $\mathrm{NH}^{4} \mathrm{O}, \mathrm{C}^{2} \mathrm{O}^{4}+\mathrm{HO}$, das man durch freiwilliges Verdunsten der Lösung vom käuflichen kohlensauren Ammoniak, oder durch Behandeln derselben mit Alkohol erhält, mit dem zweifach-kohlensauren Kali isomorph sein. Deville erhielt auf diesen Wegen aber das vorstehende Salz; die Krystallform ist den Winkelmessungen zufolge nicht mit der des zweifachkohlensauren Kalis übereinstimmend.

Nach Deville's Versuchen sind das Salz $\mathrm{NH}^{4} \mathrm{O}$, $\mathrm{C}^{2} \mathrm{O}^{4}+3 / 2 \mathrm{HO}$ und das Salz $\mathrm{NH}^{4} \mathrm{O}, \mathrm{C}^{2} \mathrm{O}^{4}+2 \mathrm{HO}$ nicht bestimmte Verbindungen. Es existiren daher nach ihm nur zwei wasserhaltige Carbonate des Ammoniaks, nämlich: 1) $\left(\mathrm{NH}^{4} \mathrm{O}\right)^{2}, 3 \mathrm{CO}^{2}+3 \mathrm{HO}$, rhombisches Prisma (analog dem Natronsalze); 2) $\left(\mathrm{NH}^{4} \mathrm{O}\right), 2 \mathrm{CO}^{2}$ $+\mathrm{HO}$, rhombisches Prisma (analog dem Kalisalze). Die Analogie existirt nur in der Zusammensetzung, nicht in der Krystallform. Wahrscheinlich findet man späterhin, dass zweifach-kohlensaures Ammoniak und zweifach. kohlensaures Kali beide amorph sind. (Annal. de Chim. et de Phys. - Chem.-pharm. Centrbl. 1854. No. 32.) B.

\title{
Untersuchungen über die Fluorverbindungen.
}

Fremy hat jetzt eine Untersuchung über Fluor, Fluorwasserstoffsäure u. s. w. angestellt. Der erste Theil seiner Untersuchung behandelt die Darstellung der reinen wasserfreien Fluorwasserstoffsiuure und deren Verbindungen.

Durch Destillation des Fluorwasserstoff-Fluorkaliums in einer Platinretorte bereitet Fremy diese Säure. Dieselbe ist bei gewöhnlicher Temperatur gasförmig, wird 
aber durch eine Mischung von Fis und Kochsalz condensirt. Sie ist eine leicht bewegliche Flüssigkeit, die auf Wasser sehr heftig einwirkt, an der Luft dichte weisse Dämpfe verbreitet und das Glas sehr heftig angreift.

Die Fluorwasserstoffsëure kann auch erhalten werden, indem man in einer Platinröhre Fluorblei, das auf einem Kohlenschiffchen ruht, durch trocknes Wasserstoffgas zersetzt. Mittelst der reinen Säure hat Fremy dann die Fluorverbindungen des Zinks, Eisens, Bleies, Silbers krystallisirt, die des Zinnfluorürs in bestimmten grossen Prismen, die des Quecksilberfluorids in deutlichen Krystallen erhalten.

Eine Verbindung mit Goldoxyd (Goldsäure) und dem Platinoxyd $\mathrm{PtO}^{2}$ konnte aber nicht erzielt werden. Fremy batte einen Theil der Lösung der Frage gewidmet, ob wohl die Fluorwasserstoffsäure vielleicht eine Sauerstoffsäure sei, kommt aber durch die Resultate auf die von allen Chemikern angenommene Constitution zurück. Er findet, dass im Allgemeinen die sauren Fluoride oder Fluorwasserstofffuoride die erste Classe ausmachen. Sie bilden sich leicht und geben beim Erhitzen, wenn sie wasserfrei sind, Fluorwasserstoffsäure, indem neutrales Fluorid zurückbleibt.

Fluorwasserstoff-Fluorkalium, mit Weinschwefelsëure erhitzt, gab den Fluorwasserstoffither; er ist gasförmig und im Allgemeinen der von Dumas und Peligot entdeckten Holzgeistverbindung ähnlich. Die zweite Classe bilden die neutralen und wasserhaltigen Fluoride. Sie sind dadurch charakterisirt, dass sie, wenn man ihnen das zu ihrer Constitution gehörige Wasser entzieht, sich leicht in Oxyde und Fluorwasserstoffsäure zersetzen. Sie verhalten sich nïmlich gerade wie fluorwasserstoffsaure Oxyde; so giebt z. B. das Fluorsilber, das hierher gehört, schon beim Trocknen in der Leere Fluorwasserstoffsäure, indem sich Silberoxyd bildet. Erhitzt man dasselbe Salz wasserhaltig, so entweicht Fluorwasserstoffsäure und Sauerstoff und es hinterbleibt sehr reines Silber.

I)ie dritte Classe besteht in den wasserfreien Fluoriden. Die hierher gehörigen Salze widerstehen der Einwirkung der Wärme und können, je nach der Natur des Metalles, das sie enthalten, durch Schwefelkohlenstoff, Chlor, Sauerstoff, Wasserstoff, Wasserdampf zersetzt werden.

Die Versuche, welche Fremy zur Isolirung des Fluors anstellte, haben in dieser Beziehung noch nicht 
zu einem entscheidenden Resultate geführt. (Compt. rend. T.38. - Chem.-pharm. Centrbl. 1854. No.31.) B.

\section{Rine neue Bestimmungsmethode des Kohlenstoffes.}

C. Brunner hat die vor mehreren Jahren von den Gebrüdern Rogers gemachte Erfahrung, dass der feingepulverte Graphit und Diamant durch saures chromsaures Kali, Schwefeläure und Wasser durch Kochen vollständig in Kohlensäure umgewandelt werde, auf die Bestimmung des Koblenstoffes in organischen Verbindungen angewandt und gefunden, dass durch einen Ueberschuss von saurem chromsaurem Kali die Einwürfo von Piria, Guck elsberg u. s. w. gegen dieses Verfahren vollkommen beseitigt und aller Kohlenstoff in Kohlensäure umgewandelt werden könne. Die zehnfache Menge saures chromsaures Kali, Schwefelsäure und Wasser zerlegten Salicin und Zucker vollkommen. Die Mischung von $1 \mathrm{Grm}$. der zu untersuchenden Substanz mit der oben angegebenen Menge des sauren chromsauren Kalis wird in eine tubulirte Retorte von $60-80 \mathrm{Cub}$.-Centim. Inhalt gethan und die Retorte so gestellt, dass der Hals derselben etwas nach oben steht und die Wasserdämpfe daselbst condensirt in die Retorte zurücklaufen, damit die Concentration sich immer gleich bleibt. An den Hals wird eine 3 Fuss lange Glasröhre angepasst, welche zur Hälfte der Richtung des Retortenhalses folgt, in der zweiten Hälfte eine horizontale Richtung annimmt; dies letztere Stück des Rohres ist mit Bimssteinstückchen, die mit Schwefelsäure getränkt sind, angefüllt. Mit diesem Rohre ist durch Kautschuk ein zweites zur Aufnahme der Kohlensäure verbunden. Dies besteht in einer weiteren und einer engeren Glasröhre, die zusammengeblasen sind.

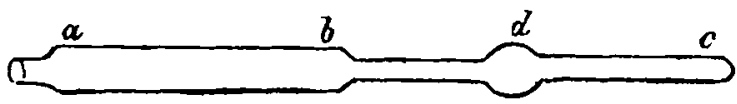

Der weitere Theil $a b$ von ungefähr 14 Centim. Länge und 2 Centim. Weite enthält ätzenden, mit Kalilauge abgelöschten und angefeuchteten Kalk; der engere Theil enthält mit Schwefelsäure befeuchteten Bimstein. Bei $a$, $b$ und $c$ aind Pfröpfe von Baumwolle leicht aingesetzt. An dies Rohr ist ein zweites befestigt welches in ein Glas mit Kalkwasser eintaucht, um den Gang der Arbeit besser beobachten zu können. Fin Apperat von den hier 